\title{
Fausto Redux: por uma nova edição do Fausto, de Fernando Pessoa
}

\author{
CARLOS PITTELLA ${ }^{1}$
}

This work discusses the fragmentary state of Pessoa's Faust and the plurality of its editions. In the dramatic work of Fernando Pessoa, the recreation of Faust occupies a central role. Though Pessoa's Faust is currently considered by critics as a "theater in ruins" (Gusmão [2003]), its main edition available presents a play supposedly organized in five acts (Pessoa, 1988). An examination of the documents that constitute this Faust reveals more than 200 disconnected fragments, mostly handwritten and undated - a puzzle whose only satisfactory solution is perhaps to accept its intrinsic incompleteness. A promising editorial possibility was presented by the University of Coimbra project Arquivo LdoD, dedicated to rethink the Book of Disquiet through an interactive online platform, with which a reader would be capable of reorganizing the textual fragments, generating her own personal anthology. This essay argues, thus, that a new edition of Pessoa's Faust would be able to re-present the great Pessoan drama in a way to honor its state of fragment, plurality and labyrinth.

FERNANDO PESSOA / FAUST / FRAGMENTS / VERSIFICATION / CRITICAL AND GENETIC EDITION

MUITOS FAUSTOS

Antes de investigar-se o que seria o Fausto, de Fernando Pessoa, é precisa uma indagação anterior: quem é Fausto? Ora, um ser humano lendário-ou mesmo arquetípico - em busca de um conhecimento quiçá impossível; um Homo sapiens entre socrático e arrogante, que sabe que não sabe, mas que acredita poder saber. À lenda fáustica, de imprecisas origens germânicas,

1 Agradeço a Filipa Freitas, Jerónimo Pizarro e José Camões, que acompanharam este trabalho. Em 2014, apresentei à Fundação para a Ciência e Tecnologia (FCT) uma proposta de reedição do Fausto pessoano e de edição do teatro inglês de Fernando Pessoa; embora bem avaliado, o projeto não seguiu adiante. Em Junho de 2015, o Centro de Estudos de Teatro (CET) da Faculdade de Letras da Universidade de Lisboa (FLUL) recebeu da Fundação Calouste Gulbenkian uma bolsa para realizar a primeira edição digital do Fausto pessoano; o CET abriu concurso para um investigador que pudesse liderar o processo de seleção e transcrição dos documentos pertencentes ao corpus da obra; minha candidatura a essa vaga foi aceita, e passei a integrar o projeto «Fausto: uma existência digital». Em 18 de Setembro de 2015, participei do I Colóquio Internacional de Genética Teatral do Centro de Estudos de Teatro (FLUL), apresentando a comunicação «Fausto Redux: uma peça em 5 atos ou 200 fragmentos?», que serviu de base para o presente artigo. 
hoje estão associados grandes nomes da literatura universal: Marlowe, Goethe, Valéry, Pessoa... para citar apenas quatro poetas que, em idiomas diferentes, buscaram recriar em verso a lenda do célebre Doutor Fausto.

Paul Valéry (1871-1945) foi contemporâneo de Fernando Pessoa (1888-1935); até onde se saiba, os dois autores não se influenciaram mutuamente em suas respectivas recriações fáusticas. Valéry surge apenas incidentalmente na biblioteca particular do poeta português, num livro não relacionado ao Fausto $^{2}$ e numa única anotação solta atribuível a Pessoa. ${ }^{3}$ Vice-versa, Valéry também não teve a oportunidade de conhecer a obra pessoana, que só viria a ser publicada de maneira consistente a partir da década de 1940, pela Ática - com fragmentos do Fausto pessoano só vindos à luz pela primeira vez em 1952.

Contudo, tanto Valéry quanto Pessoa foram grandemente influenciados por Johann Wolfgang von Goethe (1749-1832). Basta indicar que foi o simbolista francês quem proferiu, em 1932, a comunicação principal na celebração nacional alemã do centenário da morte de Goethe (vide Valéry, 1932). Tal como Goethe, Valéry era um estudioso de verve renascentista, interessado igualmente em ciências e letras. Assim como Fernando Pessoa. Curiosamente, Pessoa também havia sido convidado (por Carlos Osório de Oliveira) a escrever um artigo em homenagem ao centenário de Goethe - texto que não terminou. ${ }^{4}$

Em ordem cronológica, Christopher Marlowe (1564-1593) foi o primeiro a dramatizar a lenda do Doutor Fausto; o Faustus de Marlowe $(1604 \text { e 1616) })^{5}$ antecede em dois séculos a versão de Goethe (esta, publicada em duas partes, em 1808 e 1832), que por sua vez precede a recriação de Pessoa em um século (1908-1933).

A biblioteca particular do poeta português (Pizarro et al., 2010) conta com três edições do Faust, de Goethe ${ }^{6}$ : duas impressões da tradução inglesa de John Anster, feita em verso (1867 e 1909); e uma versão francesa, mesclando verso e prosa (sem nome de tradutor), editada por

2 Na biblioteca pessoana, é de Valéry uma «note sur l'idée de dictature», no livro Salazar: le Portugal et son chef, escrito por António Ferro e publicado em 1934, um ano antes da morte de Pessoa (vide Pizarro et al., 2010: 402).

3 Numa coleção particular em posse dos herdeiros de Pessoa, há um apontamento inédito atribuível ao poeta Português, mencionando Valéry: «imit. Valéry: Scisma um ser desegual em teu olhar tristonho».

4 Agradeço a Jerónimo Pizarro a indicação da carta de Pessoa a Osório de Oliveira.

5 As duas datas (1604 e 1616) referem-se às duas versões existentes do Faustus de Marlowe (1564-1593), ambas publicações póstumas - ainda que a peça tenha estreado durante a vida do dramaturgo inglês, entre 1588 e 1593 (não se sabe a data exata da estreia).

6 Pessoa não falava alemão, tendo acessado a obra de Goethe em traduções em inglês e francês. 
Ernest Flammarion (1907)7. Quanto ao Faustus de Christopher Marlowe, a biblioteca pessoana contém uma edição de 1912 no original inglês. ${ }^{8}$ Estes livros constituem provavelmente as fontes primárias de Pessoa para recriar a lenda milenar como obra sua. ${ }^{9}$

A lenda do Fausto antecede suas célebres apropriações por Marlowe e Goethe, remontando à Idade Média: a primeira impressão conhecida foi feita anonimamente em alemão, sob o título Historia von D. Johann Fausten (1587); tal obra seria traduzida para o inglês por P. F. Gent, como Historie of the Damnable Life, and Deserved Death of Doctor Iohn Faustus (1592).

$\mathrm{Na}$ introdução do volume de Marlowe na biblioteca pessoana, há a seguinte passagem de J. A. Symonds, mencionando as origens medievais da lenda:

[Marlowe's] Faustus is therefore a parable of the impotent yearnings of the Middle Ages-its passionate aspiration, its conscience-stricken desire, its fettered curiosity amid the cramping limits of imperfect knowledge, and irrational dogmatism. (J. A. Symonds, apud Marlowe, 1912: Iv)

É interessante notar que essa descrição se aplicaria não apenas ao lendário Fausto, mas também a muitos dos seus veros recriadores humanos - e com particular pertinência a Goethe, Valéry e Pessoa, todos eles ávidos buscadores de conhecimento. No volume de 1909 da tradução de Anster (também na biblioteca de Pessoa), outra nota - esta sobre o Faust de Goethe - perfeitamente se aplicaria a Pessoa, o poeta:

In a general sense it may be said that [Goethe's] Faust depicts the struggles of the human soul against the mean and sordid things of life. It is the story of a noble-minded searcher after Truth who "has quitted the ways of vulgar men, without light to guide him on a better way." (Nota do editor, apud Goethe, 1909: 4)

7 A biblioteca particular de Pessoa contém, ainda, um quarto livro de Goethe, sem relação com o Faust: uma compilação em prosa de poemas diversos do bardo alemão, em tradução francesa (ed. Michaud, 1909; vide Pizarro et al., 2010: 248).

8 Como pelo menos um fragmento do Fausto pessoano data de Dezembro de 1908, a primeira influência fáustica sobre Pessoa terá sido a obra de Goethe, ainda que não se possa negligenciar influências de Marlowe após 1912 - visto que o poeta português prosseguiu escrevendo o seu Fausto até o fim de sua vida, havendo fragmentos datados de 1932 e 1933 (por exemplo, os documentos de cota BNP/E3, 29-12 e 29-16, respectivamente; vide nota 14 para uma explicação sobre as cotas do espólio literário de Pessoa).

9 Pessoa também dispunha do livro Conversations of Goethe with Eckerman (Moorhead, 1930; vide Pizarro et al., 2010: 292); embora essa edição não seja diretamente relacionada ao Faust de Goethe e tenha sido publicada nos últimos anos de vida de Pessoa, ela pode ainda ter influenciado o poeta português, que continuava a elaborar o seu Fausto na década de 1930. 
O Fausto de Fernando Pessoa é uma obra incompleta, talvez inacabável -e este ensaio é uma argumentação por uma edição crítica que possa honrar a natureza fragmentária desse texto pessoano. Perante a imponente dramatização do Faustus por Marlowe e a minúcia lapidar do Faust de Goethe, a fragmentação do Fausto de Pessoa é, por contraste, ainda mais gritante.

Se, por um lado, a recriação pessoana é porventura incômoda para quem espera uma obra polida e articulada, por outro é a expressão perfeita da busca do conhecimento empreendida por Fernando Pessoa... uma busca resultando em centenas de documentos, que ainda estão à espera de uma edição que honre a sua natureza ávida, frenética, incoerente... um estado de espírito de quem busca e, quanto mais busca, mais se enreda num labirinto de palavras.

Desde 1952, quando em parte publicado pela primeira vez, o Fausto de Pessoa foi alvo de diversos estudos académicos ${ }^{10}$, traduções e, até a presente data, três diferentes edições - estas, por Eduardo Freitas da Costa (Pessoa, 1952), Duílio Colombini (Pessoa, 1986) e Teresa Sobral Cunha (Pessoa, 1988).

Não se pretendendo exaustiva, a edição inaugural de Costa é, antes de tudo, uma antologia: fragmentos atribuídos ao Fausto surgem organizados em quatro temas principais - os quais foram identificados e nomeados não por Pessoa, mas pelo editor. Colombini, por sua vez, limitou sua edição ao que considerou o «Primeiro Fausto» pessoano (Pessoa chegou a projetar três Faustos, havendo manuscritos atribuídos a uma ou outra obra fáustica). Numa terceira edição, Cunha não julgou produtiva a distinção editorial de Colombini, incluindo todos os fragmentos que pôde atribuir a um Fausto pessoano particular (primeiro, segundo ou terceiro) e textos sem distinções de pertencimento a um ou outro Fausto (ainda que atribuíveis a um Fausto geral).

Apesar de suas divergências editoriais, tanto Colombini quanto Cunha - diferentemente de Costa - intentaram editar um Fausto completo, organizando as peças deste quebra-cabeças pessoano num todo que julgaram coerente. Para tanto, os editores apoiavam-se numa 
descrição geral da peça feita por Pessoa, um documento interpretado pelos editores como uma espécie de mapa geral da obra. À medida que fragmentos foram justapostos em busca da unidade pretendida, o papel do editor aproximou-se, perigosamente, do de coautor.

Uma nova edição crítica deveria evitar, tanto quanto possível, impor ao texto de Pessoa uma coerência global que os seus fragmentos (ou poemas independentes) simplesmente não exibem. $\mathrm{O}$ estabelecimento de um aparato genético e a datação dos fragmentos que compõem a peça alterariam tanto a atual fixação quanto a sequência dos textos, provendo, assim, material para novas traduções, estudos e adaptações teatrais.

Os livros mais representativos até hoje escritos sobre o Fausto pessoano, nomeadamente O Poema Impossível (Gusmão, 1986) e Pessoas Faust (Lasch, 2006), advogam pela dispersão essencial da obra - um projeto condenado à incompletude desde a sua própria concepção. O livro pioneiro de Gusmão, baseado em sua tese de licenciatura, explora os diversos sentidos de impossibilidade (temática, formal, dramática, existencial, etc.) nesse drama:

A impossibilidade múltipla (que, como também já se viu, nasce desta situação e a determina) é experimentada (instaurada, percorrida), explícita e implicitamente, pelas formas de dizer (privilegiadamente a negação, a exclusão, o paradoxo) e pelo jogo obsessivo das antinomias de sentido. Ela revela-se duplamente no movimento impossível no que os conhecidos desenham, e na impossibilidade de conseguir, com tais fragmentos o poema dramático concluso (resolvido). (Gusmão, 1986: 131)

Muitos artigos foram escritos sobre o Fausto pessoano, destacando-se os de Lind (1962), Bene (1970), Munno (1988), Stegagno Picchio (1989), Souza (1990), Ethurens (1997), Quillier (1997) e Gusmão (2003). Ainda que publicados ao longo de quarenta anos, esses trabalhos apontam para um entendimento similar do Fausto como um texto irremediavelmente fragmentário. Nesse sentido, de modo muito similar ao Livro do Desasocego (Pessoa, 2010), o Fausto jamais teria alcançado uma unidade além da realidade dispersiva dos seus fragmentos - mesmo que Pessoa alguma vez tenha concebido o enredo na sua totalidade; decerto, se a descrição geral do enredo fáustico pode ser interpretada como um mapa, também pode ser visto como apenas um fragmento em meio a fragmentos. 
Um segundo editor, simplesmente por não ser o primeiro, desfruta de uma posição editorial privilegiada; tratando-se da obra pessoana - essencialmente incompleta, manuscrita ${ }^{11}$ e semi-legivel -, a dívida do segundo editor para com o primeiro não pode ser negligenciada. Assim, por mais lapsos de transcrição que Costa tenha cometido ao decifrar, pela primeira vez, uma seleção de manuscritos do Fausto, tanto Colombini quanto Cunha puderam confrontar as suas revisões editoriais com as escolhas do primeiro editor. ${ }^{12}$ Um novo editor do Fausto, hoje, teria a posição ainda mais vantajosa de contar com os trabalhos de Colombini e Cunha; estes, embora discordantes nas suas decifrações, apresentam meditadas opções de transcrição de documentos de difícil leitura, que um novo editor poderia pesar segundo uma metodologia crítica. A par da vantagem de uma posição editorial privilegiada, existe uma responsabilidade proporcional - a responsabilidade de que fala um dos editores de Fernando Pessoa:

Um aspecto fulcral da edição de inéditos é a responsabilidade: um editor deve optar e tomar as decisões que o autor não tomou ou sobre as quais não deixou indicações manifestas. Como organizar os fragmentos destinados a uma obra? Que variante integrar no texto «público», em detrimento de outra, se o autor não indicou a sua preferência ou hesitou mais do que uma vez? A qual das versões dar mais relevo, se forem múltiplos os testemunhos de um escrito? Dado que as respostas a estas perguntas não são unívocas e dependem de critérios mutantes, é natural e expectável que o texto inédito - comparativamente ao texto editado - possa tornar-se uma realidade múltipla. (Pizarro, 2012: 213)

Perante essa responsabilidade, três aspectos de uma nova edição crítica justificariam reeditar o Fausto pessoano: 1) redefinir o corpus da obra, incluindo documentos do espólio pessoano que possam ter passado despercebidos aos editores anteriores e excluindo textos cuja atribuição ao Fausto é duvidosa; 2) rever as transcrições, com o apoio da versificação, a fim de estabelecer um aparato genético; e 3 ) tentar datar os fragmentos da obra, propondo-se novas formas de organização do texto.

11 Embora haja datiloscritos entre os mais de duzentos documentos relativos ao Fausto pessoano, eles são poucos (cerca de dez); números exatos poderiam ser dados por uma edição crítica. 
Além das questões relativas à ordem dos poemas e à imposição de uma coerência artificial sobre a obra pessoana, há o problema mais elementar da inclusão ou não dos poemas na obra Fausto em primeiro lugar - visto que os critérios de atribuição de um texto ao Fausto não são necessariamente transparentes nas edições já realizadas. Assim, desde 1988 - data de sua mais recente edição -, o corpus conhecido do Fausto permanece intocado.

A edição de Cunha (a mais recente e englobante das três edições existentes) não indicou consistentemente se Pessoa dubitou fragmentos manuscritos; não apontou se fragmentos incluíam frases ou notas em inglês (além de português); nem considerou se os fragmentos continham indicações explícitas, implícitas ou duvidosas de pertencimento ao Fausto.

Este último ponto é crucial, pois hoje sabemos que um editor não deve interpretar o fato de documentos estarem num envelope intitulado «Fausto» como um sinal de certeza de que tais papéis teriam sido lá postos pelo próprio Pessoa. ${ }^{13}$

Um novo editor, portanto, deve procurar outros argumentos para justificar a atribuição dos textos. Pizarro (2008: 42) apresenta um documento $\left[\mathrm{BNP} / \mathrm{E}_{3}, 29-8^{\mathrm{v}}\right]^{14}$ para ilustrar esse problema. Embora publicado por Cunha (Pessoa, 1988: 154) como parte do corpus, o fragmento não inclui indicações explícitas que permitam associá-lo ao Fausto; o manuscrito encontra-se inteiramente rasurado, o que Cunha menciona apenas em nota, desconsiderando o título em inglês e a linha final presentes no documento. Pizarro (2008: 42) comenta: «muy seguramente textos como éste pasarán a un apéndice y serán retirados del corpus del drama». Uma nova edição crítica poderia estabelecer quantos poemas deveriam ser removidos ou acrescentados ao corpus, fundamentando-se em argumentos de atribuição e num aparato genético.

13 Diversos pesquisadores e arquivistas interferiram na organização do espólio pessoano (vide Santos et al, 1988; e Brown, 2015: 264).

14 BNP é o acrônimo da Biblioteca Nacional de Portugal, em Lisboa, onde se encontra o Espólio 3 (E3), com os documentos de Fernando Pessoa - estes, organizados em envelopes e folhas (estas, marcadas com «rr e «vv», respectivamente para «rosto» e «verso»). 
O propósito de um aparato genético é representar, tão fielmente quanto possível, a sucessão de variantes de uma linha ou verso e, assim, amparar a edição da última versão dedutível do texto - entendida como a última vontade do autor (vide Castro, 1990: 8).

Colombini (1986) e Cunha (Pessoa, 1988) contribuíram para tal aparato, ao anotar algumas variantes; no entanto, nenhum deles decifrou as variantes riscadas pelo poeta ou aplicou a metodologia hoje adotada por edições críticas da obra pessoana. Freqüentemente, a leitura de uma variante riscada auxilia a decifração de uma palavra de difícil leitura alhures. Além disso, uma nova edição do Fausto requereria um estudo de sua versificação - ferramenta fundamental para a fixação do texto de manuscritos em poesia, tal como argumentou Ferrari (2012).

Na introdução à sua edição, Cunha (Pessoa, 1988: XVII) sugeriu, erroneamente, que o drama estava escrito em verso livre: «os trechos inéditos, em verso livre, que, sob o título de "Primeiro Fausto", surgiam a público»; um dos primeiros estudiosos do Fausto (Bene, 1970: 64) repetiu essa percepção problemática. Já Colombini notou a métrica predominante do drama, ainda que não tenha dado à acentuação rítmica um papel determinante na fixação dos textos: «Ter observado que, embora sejam brancos os versos, há neles uma tendência à regularidade métrica, dez sílabas poéticas, constitui ajuda apenas relativa» (apud Pessoa, 1986: 11).

Embora o Fausto de Pessoa esteja escrito majoritariamente em decassílabos, a proporção exata da presença deste metro seria uma das tarefas da nova edição crítica. Além disso, em se tratando de uma peça inacabada e não publicada durante a vida do poeta, os documentos que lhe constituem encontram-se em diferentes estágios de acabamento; isso implica o fato de o texto ser passível de conter erros e inconsistências - inclusive de natureza métrica - que o poeta não tenha tido tempo de rever ou corrigir. Entretanto, uma vez reconhecido como predominante, o metro decassilábico desta obra pode decidir questões de transcrição. Por exemplo, Cunha e Pero transcrevem diferentemente a seguinte linha: 
Os demais versos da mesma estrofe são decassílabos, e apenas a transcrição de Cunha mantém o metro. Assim, embora Pessoa possa ter cometido deslizes métricos, o estudo da versificação provê um ponto de referência para o trabalho de transcrição, oferecendo, neste caso, um forte argumento para a transcrição feita por Cunha.

A fim de ilustrar o papel da análise métrica na transcrição dos manuscritos pessoanos, comparem-se as transcrições de um dos fragmentos textuais existentes no manuscrito de cota $\mathrm{BNP} / \mathrm{E}_{3}, 29-21^{\mathrm{v}}$. Costa não incluiu o texto em sua antologia; as diferenças de transcrição por Cunha e Colombini estão grafadas, assim como as opções editoriais de uma nova proposta de transcrição.

\begin{tabular}{|l|}
\hline TRANSCRIÇÃO POR CUNHA \\
(PESSOA, 1988: 21-22) \\
\hline E assim estou, pensando mais que todos, \\
Braços cruzados [...] além da fé, \\
E raciocínio, e assim sem alegria \\
Nem dúvida, além delas, da tristeza \\
De quem aqui chegou, tornado apenas. \\
Não tenho, não, já dúvida ou alegria \\
Mas nem regresso mais a essa dúvida \\
Nem a essa alegria regressara, \\
Se possível me fosse; tenho o orgulho \\
De ter chegado aqui onde ninguém \\
Nem nas asas do doido pensamento \\
Nem nas asas da louca fantasia \\
Chegou. E aqui me quedo consolado \\
Nesta perene desolação \\
\hline ESTABELECIMENTO TEXTUAL \\
\hline Estrofes: uma ou duas? \\
Fonte: normal ou em itálico (i. e. sublinhado pelo \\
autor no manuscrito original)? \\
v. 2: espaço deixado em branco pelo autor? \\
v. 4: vírgula ou travessão? \\
v. 5: «tornado» ou «turvado»? \\
\hline
\end{tabular}

TRANSCRIÇÃO POR COLOMBINI ${ }^{15}$ (PESSOA, 1986: 62-63)

E assim estou, pensando mais que todos, Braços cruzados, além da fé E raciocínio, e assim sem alegria Nem dúvida - além d'elas, da tristeza De quem aqui chegou (turvado) apenas.

Não tenho já dúvida ou alegria Mas nem regresso mais a essa dúvida Nem a essa alegria regressaria, Se possível me fosse; tenho o orgulho De ter chegado aqui onde ninguém Nem nas asas do doido pensamento Nem nas asas da louca fantasia Chegou. E assim me quedo.

Consolado nesta perene desconsolação.

\section{NOVA PROPOSTA}

E assim estou, pensando mais que todos, Braços cruzados além da fé,

E raciocínio, e assim sem alegria

Nem duvida - além d'ellas, da tristeza

De quem aqui chegou, tornado apenas.

Não tenho já dúvida ou alegria

Mas nem regresso mais a essa dúvida

Nem a essa alegria regressara,

Se possivel me fosse; tenho o orgulho

15 Os versos em itálico foram assim publicados na edição de Colombini, a indicar material até então inédito. 


\begin{tabular}{|l|}
\hline ESTABELECIMENTO TEXTUAL \\
\hline v. $6:$ «não» entre «tenho» e «já»? \\
v. $8:$ «regressara» ou «regressaria»? \\
v. $13:$ «aqui» ou «assim»? \\
vv. $13 / 14:$ «consolado» no v. 13 ou v. 14 ? \\
v. $14:$ «desolação» ou «desconsolação»? \\
\hline
\end{tabular}

Tendo em conta que este poema (ou fragmento de poema) apresenta versos decassilábicos, é possível decidir pelo menos duas dúvidas de transcrição: «regressara» ou «regressaria» no v. 8 e «desolação» ou «desconsolação» no v. 14. Apenas as opções «regressara» (oferecida por Cunha) e «desconsolação» (oferecida por Colombini) mantêm a métrica dos seus respectivos versos («regressaria» tornaria o v. 8 demasiado longo e «desolação», o v. 14 demasiado curto).

\section{O PROBLEMA DA ORDENAÇÃO}

Como ordenar uma constelação? As edições do Fausto até a presente data (Costa, 1952; Colombini, 1986; e Cunha, 1988) apresentam ordenações distintas do texto pessoano.

Como já mencionado, Costa não organizou a obra em atos, apresentando uma seleção de textos segundo temas. Já Colombini e Cunha tentaram, ambos, concretizar o plano esboçado por Pessoa no documento BNP/E3 29-5 \& 6, chegando a seqüências textuais completamente distintas: para um exemplo, vejam-se as primeiras páginas das duas edições.

Nenhum dos editores apresenta argumentos críticos para justificar as suas ordenações; Colombini seleciona um texto de 1908 e Cunha um poema de 1933 para a abertura do drama - sendo essas datas diametralmente opostas no longo período de composição do Fausto. Note-se que abrir o drama com uma das passagens mais antigas do Fausto (i. e., 1908) não significa, porém, que tenha sido assumida uma ordenação cronológica - pois Colombini (ou qualquer outro editor) jamais realizou uma datação aproximada dos documentos sem indicação explícita de data (e a maioria absoluta dos documentos da obra não tem data explícita).

As tentativas de organização do Fausto num todo coerente e artificial geraram críticas, como a formulada por Souza:

Por que não publicar os fragmentos como eles existem, isto é, versos soltos, instantâneos da criação do poeta? (Souza, 1990: 88) 
Desde 1988, edições da Imprensa Nacional-Casa da Moeda, da Assírio \& Alvim, da Nova Série da Ática e da Tinta-da-china exploraram novos territórios da obra pessoana até então inédita; além disso, todos os manuscritos pessoanos encontram-se hoje digitalizados e disponíveis em computadores da Biblioteca Nacional de Portugal. Esses dois importantes desenvolvimentos permitem pesquisar novos textos relacionados ao Fausto pessoano, fora dos núcleos já conhecidos.

Uma nova edição crítica esforçar-se-ia por datar todos os fragmentos do Fausto, ainda que aproximadamente, em busca de uma ordenação da peça alternativa àquela em temas ou atos. Lasch (2006: 24) comenta a dificuldade de datar os fragmentos, o que requer comparações de tipos de papéis e tintas usados no Fausto com os materiais já datados em outros nichos do espólio pessoano.

Dos poucos fragmentos com datação explícita (entre eles, um de 1908 e outro de 1933), infere-se que o Fausto, tal como o Livro do Desasocego (LD), acompanhou Pessoa ao longo de sua vida - e, portanto, uma cronologia poderia permitir um estudo da transformação da poética pessoana ao longo de décadas.

EDITAR E REEDITAR...

É difícil medir o impacto de uma nova edição crítica no mundo dos estudos pessoanos. Como estudo de caso, a edição crítica do $L D$ (por Pizarro, em 2010) alterou substancialmente o modo como lemos a obra-prima em prosa de Pessoa, ao retranscrever múltiplos fragmentos e ao reordená-los por completo. É provável que uma edição crítica do Fausto tenha um impacto comparável.

Dada a inerente incompletude do $L D$ e do Fausto («dois textos fragmentários, não só inacabados mas também inacabáveis», nas palavras de Gusmão, 2003: 70), uma promissora possibilidade editorial é abordar o Fausto tal como o projeto Arquivo LdoD (da Universidade de Coimbra) tem abordado o $L D$ - isto é, através de uma plataforma online interativa em que o leitor possa comparar as diversas edições publicadas do texto e, assim, reorganizar a leitura dos fragmentos de modos diversos. No início do projeto, seus objetivos foram assim descritos:

Os três principais objetivos da edição/arquivo digital são: (a) representar a dinâmica dos atos de escrita e de edição na produção do LdoD; (b) 
explorar o potencial do meio digital para recriar a história dessa dinâmica; e (c) criar um espaço de virtualização do $L d o D$ que favoreça novas dinâmicas de leitura, de edição e de investigação no confronto dos leitores com esse corpus material de fragmentos escritos. (Portela, 2013)

Num relatório dos trabalhos (Portela, 2015), esta iniciativa da Universidade de Coimbra recebeu o título mais extenso Nenhum Problema Tem Solução: Um Arquivo Digital do LdoD, e o projeto atualmente encontra-se em fase de teste, no endereço http://ldod.uc.pt/. Perante as novas possibilidades oferecidas por uma edição digital como a do Arquivo LdoD, convém resgatar a profunda pergunta proposta por Pizarro:

Toda a edição tem profundas e duradouras implicações críticas e contribui para formar a imagem de um autor. Porquê? O que significa editar? (Pizarro, 2012: 211)

Creio que esta pergunta deva ser proferida por qualquer investigador que deseje justificar um novo projeto editorial da obra pessoana. Trata-se de uma pergunta cuja resposta ideal seria a própria edição ou reedição da obra, explicitando-se os critérios empregados no estabelecimento do texto. Nesta defesa de uma nova edição do Fausto pessoano, à guisa de conclusão, urge uma resposta temporária para essa pergunta fundamental: ora, a meu ver, sem uma nova edição crítica que considerasse a fragmentação essencial da obra pessoana, é como se o Fausto de Fernando Pessoa ainda não existisse.

\section{REFERÊNCIAS BIBLIOGRÁFICAS}

BENE, Orietta del (1970), «Elementos para uma tentativa de estudo do "Primeiro Fausto" de Fernando Pessoa», Revista Ocidente, LXXVIII, 382 (2), pp. 45-75.

BLANCO, José (2008), Pessoana, 2 vols., Lisboa, Assírio \& Alvim.

BRown, Susan (2015), «From Michael and Teca: two unpublished letters to Hubert Jennings», Pessoa Plural, n. ${ }^{\circ}$ 8 (número especial Jennings), Providence / Warwick / Bogotá, Brown University, Warwick University, Universidad de los Andes, Outono, pp. 249-64.

CAS Tro, Ivo (1990), Editar Pessoa, Lisboa, Imprensa Nacional-Casa da Moeda.

ethurens, Pascal (1997), «Le Faust de Pessoa: poétique et dramaturgie», Colloque de Cerisy. Pessoa. Unité, Diversité, Obliquité, pp. 311-66.

FERrARI, Patricio (2012), «Genetic Criticism and the Relevance of Metrics in Editing Pessoa's Poetry», Pessoa Plural, n. ${ }^{\circ}$ 2, Providence / Warwick / Bogotá, Brown University, Warwick University, Universidad de los Andes, Outono, pp. 1-57. 
FER RO, António (1934), Salazar: le Portugal et son Chef, trad. Fernanda de Castro, «précédé d'une note sur l'idée de dictature par Paul Valéry», Paris, Bernard Grasset.

GOETHE, Johann Wolfgang von (1909), Goethe's Faust, trad. John Anster, Londres, Cassel \& Company.

-- (1907), Werther - Faust-Hermann \& Dorothée, Paris, Ernest Flammarion.

-- (c. 1907), Goethe: Lieds, Ballades, Odes, Poésies Diverses, Sonnets, Épigrammes, Élégies, Prométhée, Divan OrientalOccidental, ed. Alphonse Séché, Paris, Louis Michaud.

-- (1867), Faust by Goethe [translated] from the German, trad. John Anster, Leipzig, Bernhard Tauchnitz, Londres, Sampsonlow, Son \& Marston, Paris, Reinwald.

GUSMÃo, Manuel (2003), «O Fausto - um teatro em ruínas», Românica, Revista de Literatura do Departamento de Literaturas Românicas da FLUL, n. ${ }^{\circ}$ 12, pp. 67-86.

-- (1986), O Poema Impossível. O «Fausto» de Pessoa, Lisboa, Caminho.

LASCH, Markus (2006), Pessoas Faust: fragmente einer subjektiven Tragödie, Berlim, Rombach Verlag.

LIND, Georg Rudolf (1962), «Notas sobre o “Fausto” de Fernando Pessoa», Colóquio - Revista de Artes \& Letras, 18 (5), pp. 155-62.

MARLOWE, Christopher (1912), The Tragical History of Doctor Faustus, ed. Israel Gollancz, Londres, J. M. Dent \& Sons Ltd. / Aldine House.

MOORHEAD, J. K. (1930), Conversations of Goethe with Eckermann, trad. John Oxenford, Londres, J. M. Dent \& Sons; Nova Iorque, E. P. Dutton \& Co.

MUNNo, Amina di (1988), «Fernando Pessoa e il suo "patto con il diavolo"», Quaderni, 1524, Giardini Editori e Stampatori, 1984-1988, pp. 245-57.

PERO, Cecilia (1997), «Proposta di contributo alla trascrizione del "Fausto" di Fernando Pessoa», Annali della Facoltà di Lettere e Filosofia (Università di Siena, XVIII), apresentação de Antonio Tabucchi, Siena, Edizioni Cadmo, 1997, pp. 277-343.

PESSOA, Fernando (2010), Livro do Desasocego, ed. Jerónimo Pizarro, Lisboa, Imprensa Nacional-Casa da Moeda.

-- (1988), Fausto: Tragédia Subjectiva (fragmentos), ed. Teresa Sobral Cunha, prefácio de Eduardo Lourenço, Lisboa, Editorial Presença. [Reimpressão: Lisboa, Relógio D’Água Editores, 2013.]

-- (1986), Primeiro Fausto, ed. Duílio Colombini, São Paulo, Epopéia.

-- (1952), «Poemas Dramáticos de Fernando Pessoa», 1. ${ }^{\circ}$ vol. Obras Completas de Fernando Pessoa, VI, ed. Eduardo Freitas da Costa, Lisboa, Ática.

pizarro, Jerónimo, ferrari, Patricio e CARdiello, Antonio (2010), A Biblioteca Particular de Fernando Pessoa / Fernando Pessoa's Private Library, Alfragide, Publicações Dom Quixote.

PIZARro, Jerónimo (2012), Pessoa Existe? Lisboa, Ática.

-- (2008), La mediación editorial - sobre la vida póstuma de lo escrito (tese de doutoramento), Cambridge, Harvard University.

PORTEla, Manuel (2015), No Problem Has a Solution: A Digital Archive of the Book of Disquiet, Coimbra, Centro de Literatura Portuguesa da Faculdade de Letras da Universidade de Coimbra, www.uc.pt/fluc/clp/inv/proj/ ldod, 12 de Novembro (acedido a 7 de Novembro de 2016).

-- (2013), «Nenhum Problema Tem Solução: Um Arquivo Digital do Livro do Desassossego», Projeto LDOD, Coimbra, Centro de Literatura Portuguesa da Faculdade de Letras da Universidade de Coimbra, https:// projetoldod.wordpress.com/2013/10/18/nenhum-problema-tem-solucao-um-arquivo-digital-do-ldod/, 18 de Outubro (acedido a 7 de Novembro de 2016).

QUillier, Patrick (1997), «La dramaturgie paradoxale de Faust: “tragédie du sujet” et tragédie de l'oreille», Colloque de Cerisy. Pessoa. Unité, Diversité, Obliquité, pp. 427-51.

SAntos, Maria L. N. dos, CRUZ, Alexandrina, MONTENEgro, Rosa M. e PIMENTEL, Lídia (1988), «A inventariação do espólio de Fernando Pessoa: tentativa de reconstituição», Revista da Biblioteca Nacional, série II, 3 (3), Setembro -Dezembro de 1988, Lisboa, Biblioteca Nacional, pp. 199-213.

souzA, Josiane Maria de (1990), «A Geração de Orpheu. O Fausto de Fernando Pessoa: a totalidade inatingível», Remate de Males, 10, Campinas, Departamento de Teoria Literária da Linguagem, Unicamp, pp. 85-90. 
Stegagno PICChio, Luciana (1989), «La Waterloo di Pessoa», Repubblica, Roma, 13 de Dezembro de 1989. [Re-impresso sob o título «Faust: la Waterloo di Pessoa». Nel Segno di Orfeo. Fernando Pessoa e L'Avanguardia Portoghese, Gênova: Il Nuovo Melangolo, 2004, pp. 167-71.]

VALÉRY, Paul (1932), Discours en l'honneur de Goethe, Paris, La Nouvelle Revue Française.

\section{CARLOS PITTELLA}

Carlos Pittella (Brown University, Department of Portuguese \& Brazilian Studies / Faculdade de Letras da Universidade de Lisboa, Centro de Estudos de Teatro) - é poeta, investigador, educador e doutor em Letras com uma tese sobre os sonetos de Fernando Pessoa (PUC-Rio, 2012). É autor de civilizações volume dois (Palimage, 2005), co-autor de Como Fernando Pessoa Pode Mudar a Sua Vida (Tinta-da-china Brasil, 2016) e editor de People of the Archive (Gávea-Brown, 2016). Foi professor titular do Global Citizenship Experience em Chicago, onde trabalhou de 2010 a 2014. Em 2015, afiliou-se ao Centro de Estudos de Teatro (Universidade de Lisboa) para a edição digital do Fausto pessoano. Em 2016, organizou um colóquio sobre o arquivo de Hubert Jennings na Brown University, onde actualmente faz seu pós-doutoramento. 